\title{
Empréstimo de dispositivos de leitura em bibliotecas: análise de experiências
}

\section{Liliana Giusti Serra}

\author{
Doutoranda em Ciência da Informação na \\ Universidade Estadual Paulista, UNESP
}

José Fernando Modesto da Silva

Doutor em Ciências da Comunicação pela Universidade de São Paulo, USP

http://dx.doi.org/10.1590/1981-5344/2701

Os livros digitais estão aumentando sua presença nos acervos das bibliotecas. Contudo, sua inclusão nas rotinas bibliotecárias causa dúvidas, desde as possibilidades de aquisição, às formas de acesso e utilização pelos usuários. O objetivo deste artigo é alertar as bibliotecas brasileiras para o processo de implantação dos livros digitais por meio de empréstimo de dispositivos de leitura. Metodologicamente, trata-se de estudo descritivo exploratório, que por meio de levantamento bibliográfico elabora revisão de literatura sobre as experiências que identificam aspectos positivos e negativos na adoção e uso de dispositivos de leitura como forma de acesso dos conteúdos digitais. São analisadas as experiências da River Forest Public Library e Mentor Public Library (MPL). Na discussão dos resultados, elenca-se recomendações que devem ser consideradas pela biblioteca ao optar pela implantação de serviço de empréstimo de dispositivos de leitura. As considerações finais destacam que a inclusão de dispositivos de leitura em bibliotecas e sua circulação são iniciativas interessantes, mas não podem ser consideradas políticas para acesso de livros digitais pelos usuários. Entretanto, pode ser adotada por instituições que ainda não estão familiarizadas com os dispositivos e com a experiência da leitura de livros digitais.

Palavras-chave: Livros digitais; Dispositivos de leitura; Empréstimo digital. 


\title{
Reading device loan in libraries: analysis of experiences
}

\begin{abstract}
There is an increasing presence of digital books in library collections. However, their inclusion in library routines causes doubts towards their acquisition possibilities, as well as the way they can be accessed by patrons. This article alerts Brazilian libraries about the process of using digital books through lending of reading devices. Methodologically, it is a descriptive exploratory research, which collects and reviews the literature related to experiences with lending reading devices, analyzing their good and bad aspects in regards to using them to provide patrons with access to digital content. It analyzes the experiences of River Forest Public Library and Mentor Public Library (MPL) in this area. The article concludes that including reading devices is an interesting initiative for libraries, but it can not be seen as a policy to provide digital content access to patrons. However, institutions who are not familiar with digital content can offer the loan of reading devices as a first step towards using digital books.
\end{abstract}

Keywords: Digital book; Reading devices; Digital lending.

Recebido em 04.06.2016 Aceito em 27.03.2017

\section{Introdução}

Os livros digitais são recursos de informação já presentes, e de forma crescente, nos acervos das bibliotecas. Contudo, sua inclusão nas rotinas bibliotecárias ainda causa dúvidas, desde o desconhecimento do próprio objeto, até as possibilidades de aquisição, as formas de acesso e sua efetiva utilização pelos usuários. Causam, ainda, estranheza quanto as possibilidades de uso e de fragilidade que representam em relação à sua preservação e permanência de longo prazo nas coleções.

Pesquisa realizada em 2010 constatou que os livros digitais estavam presentes em $72 \%$ das bibliotecas públicas norte-americanas, sendo que $12 \%$ das bibliotecas universitárias possuíam circulação de dispositivos de leitura, enquanto $84 \%$ dessas bibliotecas reportaram que os usuários possuíam seus próprios dispositivos para leitura de livros digitais (LIBRARY JOURNAL, 2010). Muitos dos projetos de oferta de dispositivos de leitura para empréstimo foram iniciados após 2007, reflexo do 
aumento da oferta de conteúdo e do lançamento do Kindle. Antes deste ano, os projetos não representaram aplicações expressivas, motivados, principalmente, pela existência de poucos modelos de dispositivos dedicados e pela baixa popularidade dos mesmos.

Neste aspecto, o objetivo deste artigo é abordar a circulação dos livros digitais via empréstimo dos dispositivos de leitura, como forma de alertar às bibliotecas brasileiras sobre algumas questões existentes no processo, e recomendações a serem observadas por bibliotecários ou profissionais responsáveis pelo serviço de informação.

Em termos metodológicos, por meio de estudo descritivo, baseado em levantamento bibliográfico, elabora-se uma revisão de literatura, no qual se recolhe e analisa algumas experiências sobre os empréstimos dos dispositivos de leitura realizados por bibliotecas norte-americanas, identificando aspectos positivos e negativos. São analisados os casos da River Forest Public Library, no estado de Illinois, e da Mentor Public Library (MPL), no estado de Ohio. A análise das experiências concentra-se no período de 2008 a 2010. A partir destas experiências, identificam-se os pontos recorrentes e as particularidades das iniciativas, inclusive restrições de ordem legal para aplicação de projetos desta natureza. Aspectos que podem subsidiar as possibilidades de aplicação em bibliotecas brasileiras.

\section{Livros digitais e dispositivos de leitura}

Muitas bibliotecas iniciam o contato com livros digitais por meio das obras de acesso aberto (open access) ou de domínio público, sem prender-se às restrições impostas por plataformas de fornecedores como: Digital Rights Management (DRM), formatos proprietários ou compatibilidade com dispositivos de leitura. As obras de acesso aberto ou de domínio público têm seu uso franqueado, com a complexidade repassada ao controle de validade dos links quando os títulos são incluídos aos catálogos, exigindo revisão periódica por parte dos bibliotecários, a fim de garantir que o material esteja disponível em seu sítio de origem.

O fato de iniciarmos, no Brasil, a inclusão de livros digitais com certo atraso de dez anos, quando comparado às bibliotecas dos Estados Unidos e Europa, não se mostra de todo ruim, com avanços e possibilidades de licenciamento sendo ofertadas após experiências realizadas em outras instituições. Evidentemente, a quantidade e a variedade do conteúdo, disponível em língua portuguesa, ainda é pequena se comparado com o idioma inglês, porém as editoras têm-se empenhado em lançar obras no suporte digital de forma recorrente, ampliando a oferta de títulos.

Tais lançamentos, em muitos casos, baseiam-se em projetos editoriais de obras em papel, para modelar os livros no suporte digital como uma cópia fiel do impresso. Entretanto, quando concebidas com recursos multimídia ou interatividade com o leitor, também podem ser incluídas aos acervos das bibliotecas.

O livro digital pode ser licenciado para bibliotecas por meio de fornecedores específicos. Diferentemente dos leitores que recorrem às livrarias online para licenciar os títulos de seu interesse, as bibliotecas 
podem obter estes recursos por meio de fornecedores como editores, agregadores de conteúdo e distribuidores. Os editores são os responsáveis pelas obras publicadas e podem possuir, ou não, uma plataforma própria, onde comercializam somente os seus títulos.

Os agregadores são empresas que representam editores diversos, reunindo seus títulos sob uma plataforma que controla o uso que pode ser feito dos mesmos. São alternativas para editores que não possuem plataforma própria ou que se interessam em expandir as possibilidades de licenciamento por terceiras partes.

Os distribuidores também representam os títulos publicados por diversas editoras, porém diferem dos agregadores por não possuírem plataforma própria, embora promovam a comercialização do produto de outrem. Apesar de editores e distribuidores serem boas fontes para licenciamento de conteúdo, o volume de títulos ainda é concentrado nos agregadores de conteúdo e estes, no Brasil, investem em títulos destinados ao público universitário. Em similaridade ao que ocorreu nas bibliotecas norte-americanas, observa-se no país a inclusão dos livros digitais primeiramente nas bibliotecas universitárias e, sucessivamente, nas corporativas, públicas e escolares. Curioso observar a inclusão tardia em bibliotecas escolares. Esta demora surpreende pelo fato do público, nesse segmento escolar, estar habituado às novas tecnologias e, portanto, esperava-se que sua apropriação transcorresse de forma natural, exatamente pela exposição precoce com os recursos tecnológicos e digitais. Contudo, nota-se que a oferta de conteúdo e sua aplicação em ambientes escolares, no Brasil, assemelham ao movimento ocorrido no exterior.

Os atuais modelos de negócios praticados no país estão restritos a aquisição perpétua e assinatura, sem a incidência de alugueis ou processos de licenciamento transitório onde uma aquisição é disparada a partir de iniciativa do usuário, como ocorrem nos modelos Demand Driven Acquisition (DDA) e Short Term Loan (STL). As tradicionais livrarias virtuais não oferecem livros digitais para bibliotecas, com seu foco centrado em atender o leitor, o que dificulta a aquisição. Uma alternativa adotada por algumas instituições é a aquisição de dispositivos de leitura dedicados (e-readers) ou convergentes (tablets), com a inclusão de conteúdo nos dispositivos a serem emprestados. Apesar de não ser considerada uma política de inclusão de livros digitais aos acervos, mostra-se como uma alternativa às bibliotecas que não estão seguras em relação aos investimentos e as possibilidades de licenciamento de livros digitais.

Dispositivos de leitura dedicados podem ser desafiadores para bibliotecas porque estes equipamentos são, usualmente, direcionados para o leitor individual e não para instituições. Certamente, não é difícil identificar a quantidade de vezes que um dispositivo de leitura foi emprestado. Porém, não é facilmente aparente quantas vezes um título em particular foi acessado no dispositivo (GRIGG, 2012, p. 134, tradução nossa). 
Ao emprestar dispositivos de leitura, a biblioteca permite tanto a seus usuários, quanto a sua própria equipe, o contato com os livros digitais e seus dispositivos de leitura, antes mesmo de iniciar a contratação de um fornecedor para realizar assinaturas ou selecionar títulos para aquisições perpétuas. De acordo com Porter, Weaver e Newman (2012), os livros digitais podem ser oferecidos aos usuários de três formas: 1) por meio de fornecedores, com o usuário realizando o download para seu próprio dispositivo; 2) emprestando dispositivos de leitura, na forma de um serviço; e 3) como uma loja, com equipamentos para uso disponíveis no espaço da biblioteca.

Felkner (2012) destaca que ao emprestar dispositivos, a biblioteca permite aos usuários que não possuem computadores ou equipamentos que possam ter contato e usufruir dos livros digitais presentes nos acervos. Da mesma forma, quando a biblioteca não consegue adquirir livros digitais por falta de títulos disponibilizados pelos fornecedores, a aquisição de dispositivos de leitura mostra-se uma alternativa. Contudo, esta prática é transitória, visto que existem restrições na adoção desta iniciativa, além dos investimentos na compra de equipamentos e sua manutenção. O conteúdo a ser incluído nos dispositivos deve ser identificado, buscando agrupar obras de interesses similares nos mesmos dispositivos. Deve-se definir a quantidade de equipamentos a serem adquiridos, assim como marcas e modelos, com o objetivo de impedir que restrições impeçam ou dificultem a leitura dos livros digitais. Ao selecionar um dispositivo que não seja aderente a arquivos de formatos proprietários ou ferramentas de DRM, a aquisição de conteúdo pode ser dificultada ou, até mesmo, impedida. A escolha do equipamento pode limitar 0 fornecedor a ser escolhido para realizar o licenciamento do conteúdo (WALTER, 2014). Também é sugerido que as responsabilidades do usuário que realiza o empréstimo sejam explícitas, com assinatura de termos e compromisso de utilização conforme o regulamento da biblioteca e reposição do equipamento em caso de perda ou avarias.

Em termos legais, o empréstimo de dispositivos de leitura (dedicados ou convergentes) apresentam questionamentos sobre sua validade. Algumas bibliotecas receiam que, ao empresta-los, seja caracterizada violação de contratos de licenciamento de software. A restrição não está centrada nos livros digitais presentes no dispositivo, mas no empréstimo dos dispositivos em si, visto que eles funcionam mediante utilização de software e de aplicativos instalados neste, com o uso destinado somente ao proprietário. Desta forma, ao emprestar um ereader ou um tablet, a biblioteca estaria infringindo o contrato de licenciamento do dispositivo e dos aplicativos nele instalados (FELKNER, 2012; HADDOCK, 2009; HIRTLE, 2010; PORTER; WEAVER; NEWMAN, 2012).

A capacitação da equipe da biblioteca e dos usuários mostra-se fundamental, tanto para garantir a preservação dos equipamentos, quanto a efetiva utilização dos recursos. O controle da circulação dos dispositivos de leitura deve ser mensurado, avaliando o interesse dos usuários, as 
obras consultadas, a distribuição dos conteúdos nos dispositivos e a divulgação dos recursos existentes.

\section{Relato de casos de empréstimos dos dispositivos de leitura em bibliotecas}

A Biblioteca Pública River Forest (Illinois, EUA) recebeu doação de três Kindles em 2008, e investiu US\$180,00 na compra de conteúdo, definindo três categorias temáticas: ficção, não ficção e suspense. Os dispositivos foram catalogados por categorias e disponibilizados para consulta por meio do Online Public Access Catalog (OPAC). De acordo com o relato de Dierks (2011), as obras presentes em cada equipamento não foram descritas, apenas as categorias dos equipamentos. O usuário determinava apenas se desejava emprestar o dispositivo de ficção, não ficção ou suspense.

Os usuários retiravam os Kindles protegidos em capas de couro para transporte e acompanhado de um carregador de bateria. Recebiam, também, orientações sobre como utilizá-los. Esses aparatos eram bloqueados para impedir que os conteúdos fossem apagados ou outros conteúdos fossem inseridos. O tempo de empréstimo era de três semanas, sem possibilidade de renovação. Este serviço foi oferecido apenas à comunidade registrada na biblioteca, não estando disponível para o empréstimo entre bibliotecas (EEB). Os bibliotecários não tinham como determinar quais obras eram lidas, se total ou parcialmente. Assim, não era possível identificar aquelas mais consultadas, o perfil do leitor ou acompanhar detalhes do projeto, uma vez que apenas a categoria do dispositivo era registrada. Os bibliotecários também não prepararam pesquisas de opinião dos usuários sobre a leitura realizada, quando da devolução. Quanto ao modelo de dispositivo adotado, os Kindles mostraram-se resistentes com a circulação e poucos problemas foram reportados.

O projeto agradou a comunidade atendida pela Biblioteca Pública River Forest ao permitir a seus usuários o contato com publicações eletrônicas sem a necessidade de efetuar investimento na compra de um aparato de leitura de livros digitais.

No início do programa houve a ocorrência de filas de reservas, comprovando o interesse público em experimentar a novidade. Mais de seis anos após a implantação do projeto, a página da biblioteca não faz destaque do serviço, porém os equipamentos estão descritos e disponíveis no catálogo. Não é possível precisar a quantidade de dispositivos existentes no acervo, porém, foram identificados diversos modelos de Kindles (Fire, Fire HD, Touch $3 G$ etc.). Observa-se que as obras contidas nos equipamentos estão descritas atualmente. Curiosamente, os equipamentos identificados no OPAC estavam todos disponíveis, o que pode representar: 1) o baixo interesse atual dos usuários pelo projeto; 2) que a biblioteca dispõe de outras ofertas de acesso aos livros digitais (assinaturas, aquisição perpétua, DDA etc.); 3) que muitos usuários 
optaram por adquirir seus próprios dispositivos; e 4) que a leitura digital não encontrou a aderência imaginada.

A Mentor Public Library (MPL), de Ohio, iniciou o projeto de circulação de leitores dedicados em 2010, contando com quatro equipamentos da marca Nook, produzidos pela Barnes \& Noble (renomada livraria de varejo nos Estados Unido). No início a oferta apresentou alta procura, com cada dispositivo recebendo de 20 a 30 reservas. Para atender a demanda, a biblioteca adquiriu novos equipamentos, totalizando doze. No primeiro ano da iniciativa os dispositivos somaram 214 circulações.

Antes de iniciar o projeto, a biblioteca pesquisou qual o dispositivo apropriado e a opção pelo Nook levou em consideração fatores como:

a)licenciamento: ao adquirir um livro digital para o Nook é possível inclui-lo em até seis dispositivos;

b)parceria: a biblioteca desejava realizar parceria com o fornecedor, aspecto que auxiliou na capacitação dos seus funcionários para o uso dos dispositivos;

c)fatores de ordem legal: no período de seleção do dispositivo realizados pelas bibliotecas em foco, a Amazon estava em desacordo com editores quanto à funcionalidade de leitura, por voz, no Kindle.

Para evitar questionamentos legais sobre a realização de empréstimo dos dispositivos, a biblioteca pediu autorização à Barnes \& Noble para poder circular os Nooks adquiridos. Semelhante ao projeto da River Forest, a MPL adquiriu capas para os equipamentos, visando protege-los no processo de circulação para o usuário. O conteúdo também foi bloqueado evitando a inclusão ou remoção de obras digitais. Todos os equipamentos receberam os mesmos títulos (50), com ênfase em best-sellers, e não ficção. Os equipamentos eram guardados em espaço localizados no balcão de circulação e empréstimo, e onde, também, eram recarregados após devolução. Dentro da política adotada, o valor do dispositivo, do carregador de baterias, da capa protetora e do conteúdo incluído eram apresentados aos usuários, como formalização um termo de responsabilidade. Ao emprestar um Nook, o usuário assina o termo responsabilizando-se pelo dispositivo, o seu uso, acessórios e os conteúdos. No termo constam clausulas onde o usuário se compromete a ressarcir a biblioteca, em caso de dano, avaria, perda ou furto. Na devolução do equipamento, uma nova conferencia é realizada, aferindo que tudo foi devolvido e que estão funcionando plenamente.

No início, a procura pelos dispositivos foi intensa, porém, após aquisição de novos Nooks, verificou-se que nem sempre todos estavam emprestados.

Um dos pontos fortes foi permitir, ao usuário, o contato com um dispositivo. A iniciativa agradou, principalmente, aos leitores interessados em adquirir um equipamento, mas que não estavam seguros sobre qual o modelo e marca ideais. Ao capacitar os usuários para o empréstimo do equipamento, há uma contribuição com o conhecimento das possibilidades de utilização, tornando tanto a equipe da biblioteca como os seus usuários em especialistas sobre Nook. Neste sentido, houve ocasiões em que o usuário aparecia na biblioteca com seu próprio dispositivo para receber orientações sobre como utiliza-lo e, até mesmo, como obter conteúdo.

O fato do Nook ser um dispositivo com formato proprietário, restringiu a opção de compra de títulos à livraria Barnes \& Noble. Da 
mesma forma, ao selecionar este equipamento, a biblioteca limitou, além da oferta de títulos, a própria experiência de seus usuários a uma única marca, e, inviabilizando, contato com outras opções como o Kindle ou, até mesmo, dispositivos convergentes, que permitem outras aplicações de uso, além da leitura.

No relato de caso, Porter, Weaver e Newman (2012) não informam o período de empréstimo, as obras lidas, os danos nos equipamentos, nem a política de atualização do acervo adotada. Diferentemente do projeto da River Forest, a MPL não investiu em conteúdo variado, incluindo os mesmos títulos em todos os seus dispositivos. Considerando que cada livro adquirido na Barnes \& Noble pode ser copiado para seis dispositivos, a biblioteca comprou os mesmos títulos em duplicidade. Neste aspecto, a iniciativa da River Forest mostra-se interessante, ao separar os dispositivos por temática, investindo em conteúdo variado. Por outro lado, o termo de responsabilidade da MPL resguardava a biblioteca caso algum sinistro ocorresse. Apesar do Nook não ser um aparelho oferecido no Brasil, a experiência narrada reforça as limitações na aquisição do conteúdo, quando o equipamento adotado possui formato proprietário.

\section{Análise do dispositivo de leitura em bibliotecas}

Várias bibliotecas recebem solicitações de usuários e gestores para que incluam livros digitais em seus acervos. Quando isto ocorre, muitos bibliotecários acreditam que o primeiro passo seja a aquisição de dispositivos de leitura dedicados ou convergentes. A utilização dos dispositivos de leitura em bibliotecas pode representar benefícios, porém não deve ser entendido como uma política de inclusão destes recursos no serviço de informação.

O empréstimo dos dispositivos de leitura representa uma alternativa para que bibliotecas ofereçam livros digitais a seus usuários, porém não se sentem familiarizadas com os recursos ou não estão seguras quanto ao investimento a ser feito, além da aderência de sua comunidade. Os altos custos envolvidos na compra e oferta de equipamentos aos usuários representam um risco. Considerando-se o mau uso, depreciação, manutenção, risco de perda, roubo e outros possíveis danos, a adoção deste serviço não parece vantajosa, sem considerar que não é permitida a inclusão indiscriminada de livros nos dispositivos móveis. Um aspecto a considerar, refere-se à durabilidade dos equipamentos, além do frequente lançamento de novas marcas e modelos, tornando os dispositivos obsoletos em curto prazo.

Um dispositivo de leitura armazena certa quantidade de obras. Quando o leitor empresta um equipamento, ele não leva apenas uma obra, mas um conjunto delas. Adquirir conteúdo e replica-lo em diversos dispositivos não é indicado, pois não representa a variedade de obras. Nestes casos, a biblioteca possui diversos exemplares do mesmo material, porém estão reunidos em um único aparelho. É necessário destacar que 
ao incluir estes recursos aos acervos, tanto a equipe da biblioteca, quanto os usuários devem receber uma capacitação mínima para a utilização dos dispositivos, caso contrário não saberão operar os aparelhos, e nem identificar os recursos disponíveis e realizar a leitura.

Da análise das experiências citadas, são identificadas algumas recomendações que devem ser observadas pela biblioteca ao optar pela implantação de um serviço de empréstimo dos dispositivos de leitura:

1 seleção do equipamento: e-reader ou tablet? Ambos permitem a leitura de livros digitais, porém são aparatos que possibilitam utilizações distintas. A escolha do modelo e marca influencia o tipo de publicação a ser adquirida, assim como, as funcionalidades existentes. Por possuírem tecnologia e recursos diferentes, a biblioteca deve ter clareza das vantagens e desvantagens na escolha do dispositivo. Ao optar por um determinado tipo de dispositivo dedicado, assegura-se que a sua utilização não terá outra finalidade que não a leitura. Com os tablets o uso pode se estender à navegação na internet, jogar, assistir vídeos e realizar leitura. É importante bloquear o aparelho para que aplicativos e conteúdo não sejam apagados, e nem outros sejam instalados. Além disso, a aquisição de equipamentos diferentes (Kindle, tablet etc.), permita haver diversidade de marcas, modelos, e opções de conteúdo;

2 formatos de arquivos: é necessário identificar os formatos compatíveis com os dispositivos de leitura, evitando adquirir equipamentos com restrições de formatos, e consequente impedimento da leitura. O Kindle faz uso do formato proprietário $A Z W$, porém é compatível com arquivos em formato PDF e ePub (a partir da versão Fire). O Nook adota o formato PagePerfect e apresenta a mesma limitação do Kindle. As publicações adquiridas na Amazon só podem ser lidas por aparelhos Kindle ou em tablets, desde que instalado o aplicativo da loja virtual. O mesmo ocorre com o Nook, com conteúdo restrito à Barnes \& Noble. A maioria dos dispositivos de leitura suportam conteúdos em formatos PDF e ePub;

3 tipologia de livro digital: conforme a característica de livro digital a ser adquirido, alguns equipamentos podem oferecer mais ou menos restrições. Publicações em formato PDF são acessíveis por quase todos os dispositivos. Porém, conteúdos multimídia podem encontrar restrições de uso nos aparelhos. Também ocorre dificuldades para a leitura de conteúdos ilustrados, pois nem todos os dispositivos dedicados possuem recurso para visualização de cores;

4 conteúdo: a biblioteca deve estabelecer critérios para a distribuição do conteúdo incluído no dispositivo, até para otimizar o seu empréstimo. É recomendado definir temas de 
conteúdo por dispositivo, assim as chances de mais obras serem consultadas aumentam. É interessante que sejam estabelecidos números mínimos e máximos de títulos que cada dispositivo receberá. A biblioteca também deve definir se os títulos presentes nos equipamentos serão de itens existentes no acervo, na versão impressa, ou se serão títulos novos, incluindo obras existentes somente na versão digital;

5 questões legais: verificar os riscos de infração de licenciamento com projetos de empréstimo dos dispositivos de leitura. Na literatura consultada não se localizou ocorrências de sanções sofridas pela biblioteca, porém pode haver a possibilidade de infrações de direito autoral, dependendo a legislação de cada país. Se possível, buscar orientação jurídica ou anuência do fornecedor, ou ambas;

6 quantidade de equipamentos: analisar a necessidade e a quantidade de equipamentos a serem comprados, de forma que atendam a demanda dos usuários;

7 experiência da leitura digital: como observado, os usuários demonstram interesse em utilizar os dispositivos, e a biblioteca apresenta-se como espaço atrativo para este fim. Por outro lado, os investimentos e riscos são altos e a seleção e disponibilização dos conteúdos é complexa. Nota-se, também, que o interesse dos usuários tende a diminuir com 0 tempo, por motivos não totalmente mensurados pelos relatos de experiências;

circulação e empréstimo: a biblioteca deve estipular prazos de empréstimo dos dispositivos conforme a categoria de usuário. Também deve definir as permissões para renovação e reservas dos equipamentos;

8 descarte: apesar de não haver relatos nas experiências comentadas, a política de desenvolvimento de coleção deve considerar, também, o descarte do conteúdo presente nos dispositivos, assim como dos próprios equipamentos. Caso um aparelho apresente problemas, quebre, seja perdido ou roubado, a biblioteca deve estabelecer critérios para a substituição na coleção, por exemplo: com o mesmo conteúdo, mesma marca ou modelo;

9 capacitação: tanto a equipe da biblioteca quanto os usuários devem ser capacitados no uso dos dispositivos. A equipe deve estar apta a resolver problemas ou esclarecer dúvidas dos usuários. Estes, por sua vez, devem receber orientações sobre como utilizar os dispositivos, carregar baterias e realizar leituras, minimizando os riscos de avarias aos aparelhos; 
10 proteção do equipamento: investir em capas protetoras, ou em qualquer outro material destinado à proteção dos dispositivos. Se possível, selecionar capas que protejam contra quedas;

11 divulgação: o projeto de circulação dos dispositivos de leitura deve ser amplamente divulgado e a leitura nestes aparatos incentivada, até para amenizar e justificar o investimento realizado;

12 indicadores de avaliação: a biblioteca deve coletar dados dos empréstimos realizados, categorias de usuários, conteúdos consultados e outros mais que permitam mapear a utilização dos recursos. Mesmo pesquisa de opinião deve ser realizadas com constância, avaliando o nível de satisfação dos usuários em relação ao conteúdo digital, performance do aparelho, adequação do projeto. Aspectos importantes e que colaboram para implementar ajustes e assegurar a aquisição de novos equipamentos e conteúdos.

Estas são recomendações para a adoção de um projeto destinado à circulação e empréstimo de dispositivos para a leitura de livros digitais, porém, muitas outras orientações existem ou podem surgir com a implantação do serviço. Por outro lado, fazer uso desses equipamentos é interessante à biblioteca por permitir que o usuário, que não possua dispositivos de leitura ou computador, possa consultar o acervo sob novo prisma tecnológico, além de vivenciar uma outra experiência de leitura.

\section{Considerações finais}

A inclusão dos dispositivos de leitura em bibliotecas e sua circulação e empréstimo são iniciativas interessantes a serem adotadas por instituições que ainda não estão familiarizadas com outros suportes tecnológicos, e nem com a experiência da leitura de livros digitais. Por outro lado, o serviço de empréstimo de dispositivos não pode ser entendido como política de aquisição de livros digitais. Estes dispositivos são recursos tecnológicos de rápida obsolescência e alguns modelos não permitem amplo acesso ao conteúdo digital. O empréstimo de um dispositivo pode representar a retirada de dezenas ou milhares de conteúdos por um único usuário, impedindo que todos os conteúdos sejam consultados por outros usuários durante a vigência do empréstimo. Situação que coloca o conteúdo em segundo plano, com o aparato armazenando diversas itens. $O$ investimento no equipamento é considerado alto e há riscos de danos materiais. A seleção do conteúdo e sua distribuição nos dispositivos é complexa. A própria escolha da marca e 
modelo do equipamento apresenta complexidade e contempla restrições de operação e uso.

Ao decidir pela inclusão de livros digitais no acervo, a biblioteca deve assegurar-se de buscar fornecedores que trabalhem com formatos suportados por diversos equipamentos, evitando restrições de leitura, e ampliando as possibilidades de utilização pelo público. Sempre que possível, adotar obras de acesso aberto; contratar conteúdo licenciado junto aos fornecedores que ofereçam comercialização baseados na aquisição perpétua ou assinatura. Desta forma, uma parcela maior de usuários será atendida e o grau de investimento poderá ser menor que a aquisição dos dispositivos. O cenário indica que a biblioteca deve avaliar o procedimento a ser adotado, pois ao licenciar conteúdo com fornecedores, os títulos digitais podem ser incluídos no catálogo e consultados pela internet; já a opção de distribuição dos conteúdos via empréstimo dos dispositivos pode tornar indisponíveis outras formas de acesso ao conteúdo digital.

A biblioteca deve resguardar-se nas questões de infrações na adoção do empréstimo dos dispositivos. As discussões jurídicas podem variar de acordo com a legislação de cada país e as pressões do mercado editorial. O entendimento legal orienta que a biblioteca não pode emprestar os dispositivos a seus usuários, pois estaria violando a lei de software, ao emprestar um material que é comercializado para uso privado. Estudos sobre o tema ocorrem e no Brasil tornam-se necessários.

Os livros digitais representam uma janela de oportunidades para as bibliotecas, com ampliação da oferta de conteúdo e de serviços. Introduz novos aparatos tecnológicos no processo de mediação da leitura, e propiciam uma experiência diferenciada do processo de leitura. Também provoca a necessidade de reflexões da parte do bibliotecário sobre os processos de gestão da informação bibliográfica, e de sua relação com a expectativa e demanda dos usuários. Apesar dos poucos relatos de experiências de uso de livros digitais e do empréstimo de dispositivos, em bibliotecas brasileiras, este artigo colabora para despertar o debate do tema entre a comunidade bibliotecária e suas entidades representativas.

\section{Referências}

DIERKS, B. The River Forest Public Library: experience with the Kindle. In: POLANKA, S. No shelf required 2: use and management of electronic books. Chicago: American Library Association, 2011. cap. 4. Livro eletrônico.

FELKNER, R. E-books in public libraries. In: KAPLAN, R. (Ed.). Building and managing e-book collection. Chicago: Neal-Schuman, 2012. p. 37-50. (How-to-do-it manuals).

GRIGG, K. S. Assessment and evaluation of e-book collections. In: KAPLAN, R. (Ed.). Building and managing e-book collection. Chicago: Neal-Schuman, 2012. p. 127-137. (How-to-do-it manuals). 
HADDOCK, M. BYU suspends Kindle program over legal concerns. 2009. Disponível em: <BYU suspends Kindle program over legal concerns>. Acesso em: 8 mar. 2015.

HIRTLE, P. May a library lend e-book readers? 2010. Disponível em: $<$ http://blog.librarylaw.com/librarylaw/2010/06/may-a-library-lend-ebook-readers.html>. Acesso em: 8 mar. 2015.

LIBRARY JOURNAL. Survey of ebooks penetration and use in U.S. Public Libraries. 2010. Disponível em: <http://c0003264.cdn2.cloudfiles.rackspacecloud.com/Public Ebook Report_2.pdf>. Acesso em: 8 mar. 2015.

Library

POTER, M.; WEAVER, M.; NEWMAN, B. E-book sea change in public libraries. In: POLANKA, S. (Ed.). No shelf required 2: use and management of electronic books. Chicago: American Library Association, 2012. cap. 9. Livro eletrônico.

WALTERS, W. H. E-books in academic libraries: challenges for sharing and use. Journal Of Librarianship And Information Science, S.I., v. 46, n. 2, p. 85-95, jun. 2014. Disponível em: <http://lis.sagepub.com/content/46/2/85.full\#ref-28>. Acesso em: 8 mar. 2015. 